\title{
Evaluation of the cytotoxic effect of ellagic acid nanocomposite in lung cancer A549 cell line and RAW 264.9 cells
}

\begin{abstract}
Ellagic acid nanocomposite (EAN) was prepared by direct reaction zinc oxide (ZnO) with ellagic acid (EA). The cytotoxicity of nanocomposite was examined on the A549 and RAW 264.9 cells using total protein content and MTT assays, respectively. It was found that $\mathrm{IC}_{50}$ values for A549 and RAW 264.9 cells treated with EAN was 72.3 and $24.8 \mu \mathrm{g} / \mathrm{ml}$, respectively. The amount of Bcl-2, Bax and p53 proteins as well as cytochrome $\mathrm{C}$ in the lung cancer A549 cells was determined to clarify the mechanism of action of nanocomposite in the killing of cells. The results show EAN can increase the Bax and $\mathrm{p} 53$ and cytochrome $\mathrm{C}$ for 42.2 and $11.5 \%$ at $12.5 \mu \mathrm{g} / \mathrm{ml}$ concentration, respectively. At same time, the nanocomposite can decrease the Bcl-2 protein $15.4 \%$ at above concentration. A Caspase-3 and caspase-9 result shows the apoptosis mechanism for killing cancer cells.
\end{abstract}

Keyword: Ellagic acid; Nanocomposite; Total protein content; MTT; Bax; Bcl-2; P53; Cytochrome C; Caspase-3 and Caspase-9 